\title{
The Future of Oral Physicians - A Perplexing Enigma? An Indian Survey
}

\author{
${ }^{1}$ Bailoor D N, ${ }^{2}$ Naidu G, ${ }^{3}$ Jhingan A, ${ }^{4}$ Shukla A, ${ }^{5}$ Beohar K
}

\begin{abstract}
The changing aspects of the jobs being available to the MDS graduates has been evident for some years as the number of MDS graduates is increasing and the dental school jobs are getting saturated. We wanted to explore what is the ground reality with fresh MDS graduates in Oral Medicine and Radiology specialty in different states of India.

To our knowledge such an exploratory cross sectional study has not been attempted in India.

Aim: To assess the awareness of the Oral Medicine and Radiology post-graduate students regarding the future prospects in this speciality by:

a. How difficult it was to get a placement in different dental institutions.

$b$. What were the graduates actually working as/lecturers/medical transcriptionists, or deciding to join Army dental corp.

c. Whether lady MDS graduates had more difficulty in placements after MDS

$d$. Was there any difference in the northern states and the southern states in placements.

Method: A survey was performed through a questionnaire which was answered via electronic and personal communication from 103 freshly minted post-graduate specialists of various dental colleges in India

Results: Our study revealed it is easier to get jobs in northern states, Gujarat,MP and Rajasthan as the post graduate programs have started recently. While in southern states a saturation has been noted.A shift from dentistry to newer avenues like medical transcription, the army dental corp and working as MBA in corporate hospitals was established. Women were noted to have 5 times more difficulty in placements due to their family commitments.
\end{abstract}

Keywords: Mds Career Options, Army Dental Corps, Mba Options, Medical Transcription And Dentists

\section{Introduction}

In the realm of dental health education, Oral medicine and radiology started off separately and were recognized by the Dental Council Of India in 1968 as Oral Medicine and 1971 as Oral Radiology in 1980's , this subject merged and was designated as Oral Medicine And Radiology.

The new specialty, focused on diagnosis and treatment of oral mucosal lesions, treatment of medically compromised dental patients and the ever expanding branch of maxillofacial, oral and dental imaging. This specialty has a lot of jobs in teaching institutions and health care institutions.

We wanted to do this study to find out

1. How difficult it was to get a placement in different dental institutions.

2. What were the post-graduates actually working as- lecturers/medical transcriptionists, or deciding to join Army dental corp?

3. Whether lady MDS graduates had more difficulty in joining the first job after MDS.

4. Was there any difference in the northern states and the southern states in the job position?

\section{Methods And Materials}

We targeted the post-graduate doctors of OMR specialty by designing a Performa and getting it completed at two levels.

One, we circulated these at the National IAOMR Conference, Chandigarh, Nov 2012 and two, we sent these questionnaires over e-mail.

A total of 103 completed questionnaires were available to us for analysis.

\section{Results}

- The number of states surveyed are shown in table no 1 .

- The male female ratio in our study is $\mathrm{M}: \mathrm{F}=1.8: 1$.

- In states of Rajasthan, Gujarat \& Madhya Pradesh, teaching jobs as Sr. lecturer are available to $90 \%$ doctors. 
- In Southern states of Karnataka \& Tamil Nadu, absolutely no jobs were available i.e. only $18 \%$.In Andhra Pradesh, the jobs were available in remote dental schools, but Hyderabad \& Vishakhapatnam, the dearth of jobs was evident.

- The non-specialty professions constituted of:
- Doctors with MBA (administrator)
- Doctors working in clinical research \& drug trials
- Medical transcription jobs

- Army dental corps, appeared to be an important favorite for both male \& female OMR post graduates, but the fact that OMR is not recognized as a specialty in ADC, holds back a number of dental surgeons $\&$ specialists from joining.

Female MDS post graduates had 5 times difficulty as compared to males in finding a job due to the fact that family compulsions (either parents, spouses or in-laws) did not allow them to go to locations where jobs were available. Results: The analysis of the 103 doctors resulted in the graphs illustrated.

\section{Discussion}

In our study a very small percentage of doctors $(5.0 \%)$ actually admitted to poor choice \& level of frustration in this specialty currently.In contrast, the work of J.M Zakrzweska ${ }^{1} 2001$ U.K. mentioned in their British study that one-third of the doctors regretted their choice of specialty.

The results of our study revealed, majority of the doctors in Rajasthan, Gujarat \& M.P. participated both in academics \& private practice.

In Southern states, the participation was skewed in favor of academics \& $63.0 \%$ of OMR specialists did not practice at all \& focused on teaching \& research.

The data obtained from Bailoor D N, Wanjari P , Chaudhary A, ${ }^{2}$ National IAOMR Conference Indore 2009 , regarding participation of BDS \& MDS in MBA-hospital administration as a career path was found to be increasing as seen in year 2007-2011 (table no 2 \& fig no 1..)

As per the work of Michael Rees, $1997^{3}$ published in BMJ, he reported that doctors did not like to work in academics in the U.K. as private practice was more paying \& lucrative.

According to Valantine $\mathrm{H}$, Sandborg $\mathrm{CI}^{4}{ }^{4}$ the dearth of women at the highest ranks of academic medicine not only sends a clear message to women that they must choose between career advancement and their personal life but also represents a loss of talent for academic health centers as they fail to recruit and retain the best and the brightest.

In a study done by Aggarwal AM et al.$^{5}$ in Haryana in private dental colleges, only $11.7 \%$ reported the desire to pursue dentistry for research purposes. Overall, this study found that financial and professional factors were the chief criteria for students' pursuing dentistry in India; however, the strongest influence in the choice of dentistry was the students' parents or family.

In a survey done by Shetty VB et al. ${ }^{6}$ The authors surveyed forty-five dental interns at the end of their undergraduate course, the study revealed 86 percent wanted to pursue postgraduate study, which is a strong indicator of undergraduates having high expectations from MDS

Aditya V the CEO at the Fortis health care mentions that clinical research industry is undergoing a boom and for many medical and dental professionals who have specialized knowledge, this area seems to be an promising start for alternative career. ${ }^{7}$

Medical writing is an important area in which doctors of all specialties can find suitable job opportunities. Max healthcare which is headed by Dr Vineeta Jha ${ }^{7}$ who is both a psychiatrist and an MBA says that her group of health care professionals is doing a good job of medical writing and Journal upgrading to educate others in this field. Such firms also give the doctors flexibility to work from home. This is a great advantage when the doctors have to balance family with professional life.

Territorial Army (TA) also recruits the males who have completed graduation which means that BDS and MBBS doctors can also be considered basic graduates and may serve the nation by becoming officers in the TA. $^{8}$

Trudy Brunot ${ }^{9}$ mentions that as per her statistics around ten percent of the dentist are involved professionally in Nonclinical jobs. These may include hospital management, research and criminal investigation.

Even though Zakrzewska JM et al ${ }^{10}$ mention the importance of specialty practice, in India it is very difficult for the MDS graduates to practice exclusively this profession because the awareness of the general public in dental health is so low that such specialists are still looked upon as dentists only. In teaching institutions however this specialty is recognized and respected.

As per the historical work of Nancy Tomes ${ }^{11}$, the women's professions tended to be defined specifically to nursing and other serving areas only. 
Clark EH a professor at Harvard Medical School had argued that women were biologically inferior \& that they should not be allowed in higher education .Infact, it may be noted that Harvard Medical School, did not admit women until $1945 .^{12}$

Even in our study, in the three southern states of Karnataka, Andhra Pradesh \& Tamil Nadu, the lady physicians had higher level of unemployment due to family factors, primarily

Not allowed by parents/spouses/in-laws

Were married and could not relocate to areas where jobs were available.

Married and had commitments to their children \& their husbands graduation.

These factors were seen in $\mathbf{1 5 \%}$ of women who did not find work even after 1 year after completion of post-

In the northern states like Rajasthan, Gujarat \& M.P., the jobs are available because of the fact that post-graduation has begun comparatively recently in 2010-2011, but as the no. of PGs will increase a dearth of jobs will hit this region too. The only option then would be to enter in alternative corporate career in pharmacy-vigilance, medical transcription \& hospital administration after or during their MBA training.

Alice Thompson mentions that in UK more than half the places in medical school are taken up by women her data suggests that as per the analysis of NHS (National Health Service of UK) $60 \%$ of the women doctors give up practicing. She has not analyzed the reasons but one could hypothesize that family \& social factors would predominate. ${ }^{13}$ To conclude our study revealed it is easier to get jobs in northern states as the post graduate programs have started here fairly recently. While in southern states a saturation has been noted. We found that many graduates have now shifted from practicing dentistry to newer avenues like medical transcription and also in the army dental corps. There is disappointing factor noted in the study, being that women have a lot of difficulty in starting their first jobs just after completing their MDS.

\section{Tables}

Table no. 1

\begin{tabular}{|c|c|c|c|}
\hline S.No. & States & Number & Percentage \\
\hline 1. & Madhya Pradesh & 21 & $20.3 \%$ \\
\hline 2. & Maharashtra & 28 & $27.1 \%$ \\
\hline 3. & Karnataka & 8 & $7.7 \%$ \\
\hline 4. & Tamil Nadu & 6 & $5.8 \%$ \\
\hline 5. & Andhra Pradesh & 8 & $7.7 \%$ \\
\hline 6. & Gujarat & 21 & $20.3 \%$ \\
\hline 7. & Rajasthan & 11 & $10.6 \%$ \\
\hline
\end{tabular}

Table No. 2

\begin{tabular}{|c|c|}
\hline Year & Number of BDS graduates choosing MBA \\
\hline 2007 & 9 \\
\hline 2008 & 14 \\
\hline 2009 & 19 \\
\hline 2010 & 20 \\
\hline 2011 & 32 \\
\hline
\end{tabular}

Table No. 2 Showing the gradual increase in the number of graduates who preferred to join MBA in hospital management instead of MDS.

\section{Graphs \& Figures}

Fig No.1

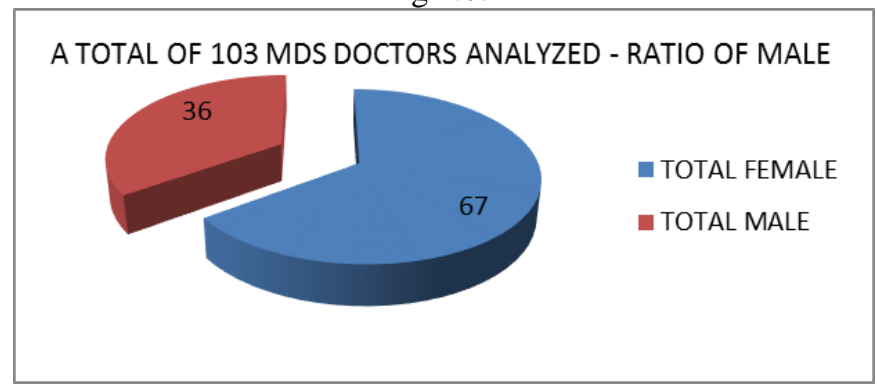

Fig. No. 1:This graph shows that in OMR specialty almost 2/3rds of the doctors were female. The trend where more women doctors are opting for this branch continues

Fig No. 2 


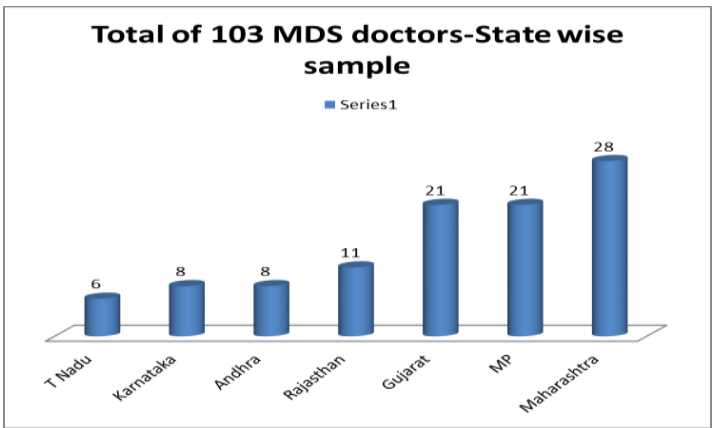

Fig No. 2: The seven states polled for this data and the number of MDS graduates were as mentioned in this graph, maximum came from Gujarat, MP and Maharashtra.

Fig No.3

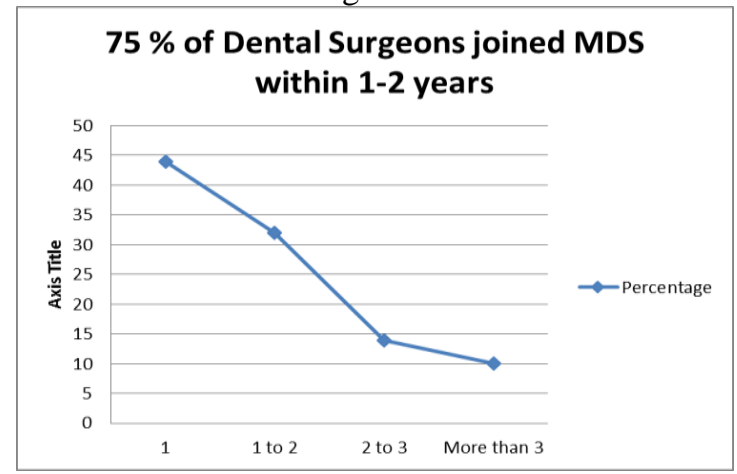

Fig No. 3 depicts that most of the MDS graduates joined for PG within 1-2 years, less than $10 \%$ took a gap of more than 3 years.

Fig No. 4

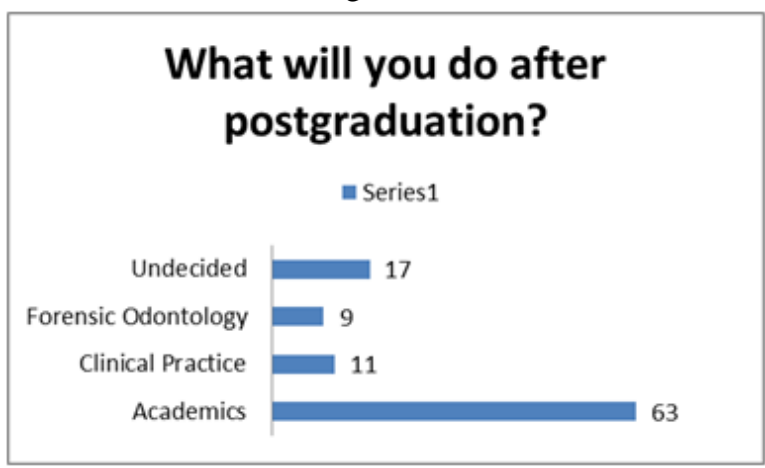

Fig No 4: Showing that almost $63 \%$ of the graduates were planning to start the work in dental schools and academics.

Fig No. 5

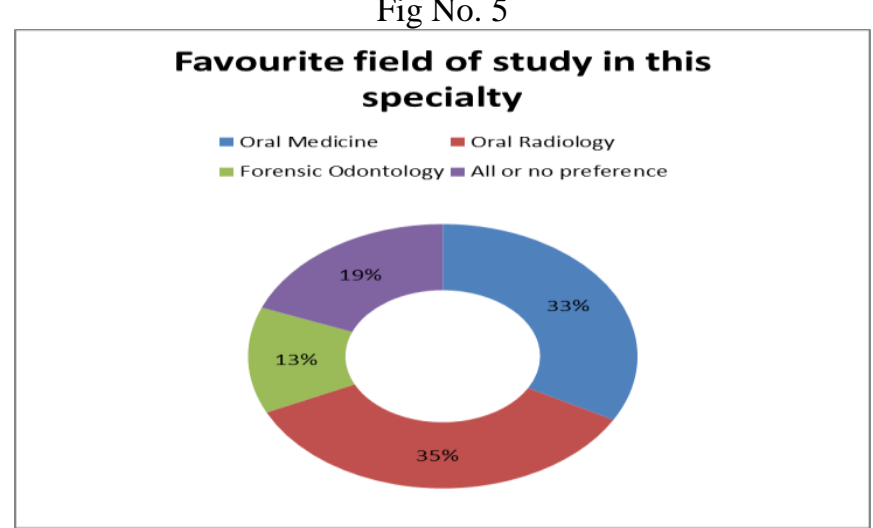

Fig No. 5 Shows that $35 \%$ of the graduates showed great interest in the Oral Radiology domain and 33\% in Oral Medicine domain rest were interested in the Forensic Odontology area. 
Fig No. 6

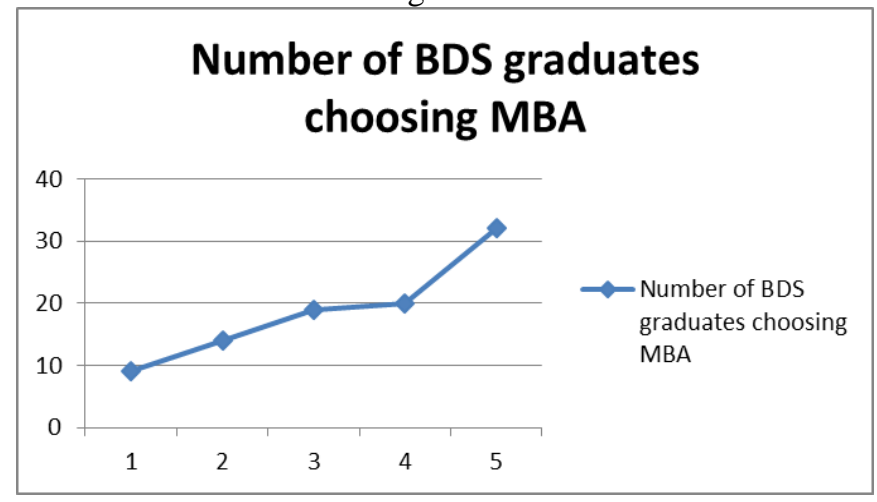

Fig no. 6: depicting the data of table no. 2

\section{References:}

[1]. Zakrazweska Training In Oral Medicine..J R Soc Med 2001;94:79-82.

[2]. Bailoor D N, Wanjari P , Chaudhary A, National IAOMR Conference Dec 2009,Indore - this study was continued till December 2011." MBA the new frontier for BDS doctors- a five year study- Key Note lecture".

[3]. $\quad$ Rees.Who Wants A Career In Academic Medicine? BMJ 1997;315:74.

[4]. Valantine H, Sandborg CI:Changing the Culture of Academic Medicine to Eliminate the Gender Leadership Gap: Acad Med. 2013 Aug 21.

[5]. Aggarwal A, Mehta S, Gupta D, Sheikh S, Pallagatti S, Singh R, Singla I J Dent Educ. Dental students' motivations and perceptions of dental professional career in India. 2012 Nov;76(11):1532-9.

[6]. Shetty VB, Shirahatti RV, Pawar P. Students' perceptions of their education on graduation from a dental school in India J Dent Educ. 2012 Nov; 76(11):1520-6.

[7]. Chaturvedi A: Clinical Research: Medical professionals chart new careers with labs,hone business acumen and managerial skills ET Bureau Economic Times Bureau Nov 30, 2012.

[8]. About TA - Territorial army recruitment http://www.ssbcrack.com/2013/06/territorial-army-notification-july-2013.html

[9]. Trudy Brunot :Alternative Careers For Dentists ., Demand Media Houston Chronicle. 2011.

[10]. Zakrzewska JM , Downer C, Lopes V. The Oral Medicine Clinic - What Is Its Role? Journal Of The Royal Society Of Medicine 1994;87:390-92

[11]. Journal of Medical \& Allied Sciences, Oct 1978

[12]. Dr E H Clark.Sex in education-or a Fair Chance for the Girls.1873 pg 47

[13]. Alice Thomson - Daily Telegraph 27/06/03 http://www.angryharry.com/ess the Training of Women Doctors A Waste.html 